\title{
The impact of Paenibacillus polymyxa HY96-2 luxS on biofilm formation and control of tomato bacterial wilt
}

\author{
Jincui Yi ${ }^{1}$ • Daojing Zhang ${ }^{1} \cdot$ Yuejuan Cheng ${ }^{1} \cdot$ Jingjing $\operatorname{Tan}^{1} \cdot$ Yuanchan Luo ${ }^{1}$ (D) \\ Received: 14 May 2019 / Revised: 27 August 2019 / Accepted: 28 September 2019/Published online: 5 November 2019 \\ (C) The Author(s) 2019
}

\begin{abstract}
The focus of this study was to investigate the effects of $\operatorname{lux} S$, a key regulatory gene of the autoinducer-2 (AI-2) quorum sensing (QS) system, on the biofilm formation and biocontrol efficacy against Ralstonia solanacearum by Paenibacillus polymyxa HY96-2. luxS mutants were constructed and assayed for biofilm formation of the wild-type (WT) strain and luxS mutants of P. polymyxa HY96-2 in vitro and in vivo. The results showed that luxS positively regulated the biofilm formation of HY96-2. Greenhouse experiments of tomato bacterial wilt found that from the early stage to late stage postinoculation, the biocontrol efficacy of the $l u x S$ deletion strain was the lowest with $50.70 \pm 1.39 \%$ in the late stage. However, the $l u x S$ overexpression strain had the highest biocontrol efficacy with $75.66 \pm 1.94 \%$ in the late stage. The complementation of luxS could restore the biocontrol efficacy of the $l u x S$ deletion strain with $69.84 \pm 1.09 \%$ in the late stage, which was higher than that of the WT strain with $65.94 \pm$ $2.73 \%$. Therefore, we deduced that luxS could promote the biofilm formation of $P$. polymyxa HY96-2 and further promoted its biocontrol efficacy against $R$. solanacearum.
\end{abstract}

Keywords Paenibacillus polymyxa $\cdot$ Quorum sensing $\cdot \operatorname{lux} S \cdot$ Biofilm formation $\cdot$ Bacterial wilt $\cdot$ Biocontrol efficacy

\section{Introduction}

With the enhancement of people's awareness of environmental protection and food safety, microbial pesticides have attracted more and more attention due to their non-toxicity, environmental friendliness, and safety toward humans and animals (Berg 2009). The microbial pesticide industry has become a "sunrise industry" in China in line with the Chinese government's policy of "two reductions," a policy that is focused on reducing the amounts of chemical pesticides and fertilizers used (Luo et al. 2018). The number of registered and commercially available biopesticides is growing sharply

Jincui Yi and Daojing Zhang contributed equally to this work.

Jincui Yi and Daojing Zhang are co-first author.

Electronic supplementary material The online version of this article (https://doi.org/10.1007/s00253-019-10162-0) contains supplementary material, which is available to authorized users.

Yuanchan Luo

luoyuanc@ecust.edu.cn

1 State Key Laboratory of Bioreactor Engineering, East China University of Science and Technology, Shanghai 200237, China every year (http://www.icama.org.cn/fwb/index.jhtml). Ralstonia solanacearum is a devastating plant pathogen with a global distribution and an unusually wide host range, which could cause more than 200 plants throughout the world to be impacted by bacterial wilt (Genin and Boucher 2004). Bacterial wilt has been mainly controlled by chemical pesticides, but they are potentially harmful to the environment and have not been efficient in eradicating $R$. solanacearum (Marian et al. 2018). The use of microbial pesticides has become one of the important strategies to control plant bacterial wilt (Marian et al. 2018; Shen et al. 2017) because of their environmental friendliness, diversity of biocontrol mechanisms, and good control efficacy toward soil-borne diseases (Kalantari et al. 2018; Omomowo et al. 2018; Timmusk et al. 2019). As of December 2018, 52 microbial pesticides had been registered to control plant soil-borne diseases in China, of which 11 were registered to control plant bacterial wilt (http://www.icama.org.cn/fwb/index.jhtml).

Paenibacillus polymyxa HY96-2, which was isolated from the rhizosphere of tomato plants in the suburbs of Nanchang, Jiangxi Province, China, is a Gram-positive bacterium that has been shown to control a variety of plant diseases and promote plant growth (Fan et al. 2012; Luo et al. 2018; Xu et al. 2006b). As much as 1 billion CFU/g wettable powder of 
P. polymyxa HY96-2 has been developed and industrialized by our laboratory and a cooperative company as a microbial pesticide. This pesticide was registered in China in 2004 as the first microbial pesticide based on Paenibacillus for controlling plant bacterial wilt around the world (http://www.icama.org. $\mathrm{cn} / \mathrm{fwb} / \mathrm{index} . j \mathrm{html}$; https://www.epa.gov/tsca-inventory/listsubstances-reported-under-tscainventory-notification-activeinactive-rule; http://www.ec.gc.ca/ese-ees/9F3909AA-30244BBD-AC9E-2EB681ED1BBD/ FSAR_Paenibacillus\% 20Polymyxa_EN.pdf). However, in order to provide a scientific basis for the field application technology of the pesticide with $P$. polymyxa HY96-2, further study of its biocontrol mechanism is needed. Preliminary studies suggested that $P$. polymyxa HY96-2 could control plant diseases through the mechanisms of colonization (biofilm formation), antagonism, and induced systemic resistance of plants in a similar manner as other microbial pesticides (Luo et al. 2018; Xu et al. 2006b). Among them, the most important factor for determining the biocontrol efficacy of a microbial pesticide is whether or not the biocontrol microorganisms can colonize well at the roots of the host plants (Ji et al. 2008; Li et al. 2012; Lugtenberg and Dekkers 1999). Biofilm formation around the roots of host plants is an important trait that has been linked to the colonization ability of biocontrol microorganisms (Haggag and Timmusk 2010; Li et al. 2012). Previous studies have shown that biofilm formation can improve the control efficacy of many biocontrol agents, including Bacillus subtilis (Bais et al. 2004) and P. polymyxa (Haggag and Timmusk 2010; Timmusk et al. 2009).

The colonization of biocontrol agents in the rhizosphere of host plant is strictly regulated by many environmental factors and the regulation system inside the bacteria. The quorum sensing (QS) system is one of the important factors that regulate the biofilm formation in many bacteria (Miller and Bassler 2001; Raafat et al. 2019). QS is a process by which bacteria monitor their population density and regulate gene expression by using secreted chemical signaling molecules called autoinducers (AI) (Balestrino et al. 2005; Miller and Bassler 2001). There are three typical quorum sensing systems that have been reported to date (Balestrino et al. 2005; Bassler 2002). Type 1 is a quorum sensing system mainly in Gramnegative bacteria that utilizes $N$-acyl-homoserine lactones (AHLs) as signal molecules (Galloway et al. 2011; Raafat et al. 2019; Whitehead et al. 2001). Type 2 quorum sensing system is mainly associated with Gram-positive bacteria and uses the autoinducing peptide (AIP) as a signal molecule (TalGan et al. 2016). Type 3 quorum sensing system exists in both Gram-positive and Gram-negative bacteria and uses autoinducer-2 (AI-2) as a signal molecule (Bassler 2002; Galloway et al. 2012; Liu et al. 2019; Rezzonico et al. 2012). LuxS is the product of the luxS gene, and it catalyzes the conversion of $S$-ribosyl homocysteine (SRH) to homocysteine and 4,5-dihydroxy-2,3-pentanedione (DPD) (Balestrino et al. 2005). DPD then generates AI- 2 spontaneously (Gu et al. 2018; Han and Lu 2009). As a result, luxS is a key regulatory gene of the AI-2-mediated quorum sensing system (Ma et al. 2017b).

Up until now, LuxS/AI-2 quorum sensing system research has mainly focused on human pathogens. It had been reported that $\operatorname{luxS}$ could affect the biofilm formation abilities of Escherichia coli (Niu et al. 2013), Staphylococcus aureus (Liu et al. 2019; Ma et al. 2017a), Streptococcus oralis (Rickard et al. 2006), Streptococcus pneumoniae (Vidal et al. 2011), Streptococcus mutans (Yoshida et al. 2005), and other species pathogens (Table 1), and most of their virulence could be affected by the biofilm formation regulated by luxS (Ali et al. 2018). Therefore, it could be speculated that the biofilm formation in probiotics would promote their biocontrol efficacy. There have been a few studies that have focused on the regulation of biofilm formation by $\operatorname{lu} x S$ in probiotics. Sun et al. (2014) found that the overexpression of luxS in Bifidobacterium longum NCC2705 promoted its biofilm formation (Table 1). In Bacillus, sequencing results have shown that $\mathrm{AI}-2$ was an important signaling molecule in QS systems of several species (such as B. subtilis, Bacillus cereus, Bacillus thuringiensis, and Bacillus anthracis), and luxS was the key regulatory gene of the QS systems in these organisms (Auger et al. 2006; Duanis-Assaf et al. 2015; Lombardia et al. 2006). Our previous study also showed that the QS system in P. polymyxa HY96-2 was mediated by AI-2, and its key regulatory gene was $l u x S$ (Luo et al. 2018).

To the best of our knowledge, no research focusing on the biofilm formation and biocontrol efficacy of biocontrol agents, including $P$. polymyxa, regulated by $l u x S$ has been reported. Therefore, this study is the first to address the effect of luxS on the biofilm formation of $P$. polymyxa. Using the system of $P$. polymyxa HY96-2 wild-type strain and its lux $S$ mutants against $R$. solanacearum in tomato plants, the impact of luxS on biocontrol efficacy of $P$. polymyxa HY96-2 was investigated. This study provides a scientific basis for the field application technology of the microbial pesticide derived from P. polymyxa HY96-2.

\section{Materials and methods}

\section{Bacterial strains, plasmids, chemicals, media, and growth conditions}

The strains and plasmids used in this study are listed in Supplementary Table S1, the primers are listed in Supplementary Table S2, and the chemicals are listed in Supplementary Table S3. E. coli DH5 $\alpha$ cells (Woodcock et al. 1989) were cultured in LB medium at $37^{\circ} \mathrm{C}$ with shaking at $200 \mathrm{rpm}$. P. polymyxa and its mutants were cultured in LB medium at $30{ }^{\circ} \mathrm{C}$ with shaking at $180 \mathrm{rpm}$. When necessary, 
Table 1 Summary of the effects of $l u x S$ on biofilm formation of some bacterial species

\begin{tabular}{|c|c|c|c|c|c|}
\hline Species & $\mathrm{G}^{+} / \mathrm{G}^{-}$ & Type & $\begin{array}{l}\text { Regulation of } \operatorname{luxS} \\
\text { on the biofilm } \\
\text { formation }\end{array}$ & $\begin{array}{l}\text { The mechanism of luxS affecting biofilm } \\
\text { formation }\end{array}$ & References \\
\hline $\begin{array}{l}\text { Bifidobacterium } \\
\text { breve UCC } 2003\end{array}$ & $\mathrm{G}^{+}$ & Human probiotics & Positive regulation & Unclear & $\begin{array}{l}\text { Christiaen et al. } \\
\text { (2014) }\end{array}$ \\
\hline $\begin{array}{l}\text { Bifidobacterium } \\
\quad \text { longum } \text { NCC } 2705\end{array}$ & $\mathrm{G}^{+}$ & Human probiotics & Positive regulation & $\begin{array}{l}\text { It may be a novel mechanism by which the AI- } 2 \\
\text { signal is transduced to affect QS independently } \\
\text { of a LuxPQ or LsrB-type AI-2 receptor. }\end{array}$ & Sun et al. (2014) \\
\hline $\begin{array}{l}\text { Bacillus subtilis } \\
\quad \text { NCIB3610 }\end{array}$ & $\mathrm{G}^{+}$ & $\begin{array}{l}\text { Contaminant } \\
\text { bacterium in dairy } \\
\text { industry }\end{array}$ & Positive regulation & $\begin{array}{l}\text { Lactose-induced biofilm formation depends on } \\
\text { the expression of the tapA and epsA-O operons, } \\
\text { which are responsible for biofilm matrix } \\
\text { production. Lactose enhanced the production } \\
\text { of AI-2 affected not directly on the biofilm } \\
\text { formation cascade. So, activation of biofilm } \\
\text { formation via the QS system might be an ad- } \\
\text { ditional regulatory mechanism. }\end{array}$ & $\begin{array}{l}\text { Duanis-Assaf et al. } \\
\text { (2015) }\end{array}$ \\
\hline $\begin{array}{l}\text { Capnocytophaga } \\
\text { ochracea }\end{array}$ & $\mathrm{G}^{-}$ & Human pathogens & Positive regulation & $\begin{array}{l}\text { The attenuation of biofilm formation by a } \operatorname{lux} S \\
\text { deletion strain is likely caused by a defect in the } \\
\text { activated methyl cycle rather than by a loss of } \\
\text { AI- } 2 \text {. }\end{array}$ & $\begin{array}{l}\text { Hosohama-Saito } \\
\text { et al. (2016) }\end{array}$ \\
\hline $\begin{array}{l}\text { Haemophilus } \\
\text { influenzae }\end{array}$ & $\mathrm{G}^{-}$ & Human pathogens & Positive regulation & $\begin{array}{l}\text { luxS impacts changes in lipooligosaccharides } \\
\text { (LOS) glycoform populations that are essential } \\
\text { for full biofilm maturation. }\end{array}$ & $\begin{array}{l}\text { Armbruster et al. } \\
\text { (2009) }\end{array}$ \\
\hline $\begin{array}{l}\text { Paenibacillus } \\
\quad \text { polymyxa } \mathrm{HY} 96-2\end{array}$ & $\mathrm{G}^{+}$ & Biocontrol agent & Positive regulation & - & This study \\
\hline $\begin{array}{l}\text { Streptococcus } \\
\quad \text { mutans }\end{array}$ & $\mathrm{G}^{+}$ & Human pathogens & Positive regulation & $\begin{array}{l}\operatorname{lux} S \text { regulates the glucosyltransferase genes that } \\
\text { are required for sucrose-dependent biofilm } \\
\text { formation. }\end{array}$ & Merritt et al. (2003) \\
\hline $\begin{array}{l}\text { Streptococcus } \\
\quad \text { pneumoniae D39 }\end{array}$ & $\mathrm{G}^{+}$ & Human pathogens & Positive regulation & $\begin{array}{l}\text { LuxS regulates the transcript levels of lyt } A \text {, which } \\
\text { encodes an autolysin previously implicated in } \\
\text { biofilms. }\end{array}$ & Vidal et al. (2011) \\
\hline Streptococcus suis & $\mathrm{G}^{+}$ & Animal pathogens & Positive regulation & $\begin{array}{l}\text { lux } x \text { deletion affects biofilm formation via the } \\
\text { LuxS-based signaling molecule (AI-2). }\end{array}$ & Wang et al. (2011) \\
\hline $\begin{array}{l}\text { Bacillus cereus } \\
\quad \text { ATCC } 10987\end{array}$ & $\mathrm{G}^{+}$ & Human pathogens & Negative regulation & $\begin{array}{l}\text { luxS repressed biofilm formation may be related } \\
\text { to the lsr-like genes which were involved in } \\
\text { uptake and processing of AI- } 2 \text {. The Lsr-like } \\
\text { system is present in Gram-negative bacteria, } \\
\text { but not found in any other sequenced } \\
\text { Gram-positive bacterium except Bacillus } \\
\text { cereus. }\end{array}$ & Auger et al. (2006) \\
\hline $\begin{array}{l}\text { Listeria } \\
\quad \text { monocytogenes }\end{array}$ & $\mathrm{G}^{+}$ & Human pathogens & Negative regulation & $\begin{array}{l}\text { The } \operatorname{luxS} \text { gene may associate with repression of } \\
\text { components required for attachment and } \\
\text { biofilm formation. }\end{array}$ & Sela et al. (2006) \\
\hline $\begin{array}{l}\text { Staphylococcus } \\
\quad \text { aureus }\end{array}$ & $\mathrm{G}^{+}$ & Human pathogens & Negative regulation & $\begin{array}{l}\text { The LuxS/AI-2 QS system can regulate polysac- } \\
\text { charide intercellular adhesion (PIA)-dependent } \\
\text { biofilm formation via the repression of the } r b f \\
\text { (a positive regulator of biofilm formation) ex- } \\
\text { pression. }\end{array}$ & Ma et al. (2017a) \\
\hline $\begin{array}{l}\text { Staphylococcus } \\
\text { epidermidis }\end{array}$ & $\mathrm{G}^{+}$ & $\begin{array}{c}\text { Nosocomial } \\
\text { pathogen }\end{array}$ & Negative regulation & $\begin{array}{l}\text { luxS repressed biofilm formation by decreasing } \\
\text { the transcription of intercellular adhesion } \\
\text { operon (ica) genes and production of } \\
\text { polysaccharide intercellular adhesin (PIA). }\end{array}$ & Xu et al. (2006a) \\
\hline
\end{tabular}

$G^{+}$Gram-positive, $G^{-}$Gram-negative

antibiotics were used at the following concentrations: $100 \mu \mathrm{g} / \mathrm{mL}$ ampicillin, $25 \mu \mathrm{g} / \mathrm{mL}$ chloramphenicol, and $5 \mu \mathrm{g} / \mathrm{mL}$ erythromycin; the antibiotics were purchased from Saiguo Biotechnology Co., Ltd. (Guangzhou, Guangdong, China). R. solanacearum (ATCC11696) was activated using tetrazolium chloride (TZC) selective medium
(Yang and Ho 1998) at $28^{\circ} \mathrm{C}$ for $24 \mathrm{~h}$, and the highly pathogenic colonies (pink colonies) were picked and suspended in sterile water to make an $R$. solanacearum suspension and spread on SPA plates (20 g sucrose, $5 \mathrm{~g}$ peptone, $0.5 \mathrm{~g}$ $\mathrm{K}_{2} \mathrm{HPO}_{4}, 0.25 \mathrm{~g} \mathrm{MgSO}_{4} \cdot 7 \mathrm{H}_{2} \mathrm{O}$ and $15 \mathrm{~g}$ agar per liter, $\mathrm{pH}$ 7.2 7.4) for later use. 
P. polymyxa HY96-2 was preserved in the China General Microbiological Culture Collection Center (CGMCC No. 0829). The accession number of the P. polymyxa HY96-2 complete genome sequence is CP025957, and the sequence number (locus tag) of the luxS gene of $P$. polymyxa HY96-2 is C1A50 RS02845.

\section{Construction of knockout plasmid pRN5101-Cm}

Plasmid pRN5101-Cm was constructed for gene knockout by fusing the PCR products of the chloramphenicol resistance gene cloned from plasmid pDG1661 (Kim and Timmusk 2013) with the upstream and downstream fragments of the luxS genes amplified with the primers shown in Supplementary Table S2 by insertion into to the BamHI/ HindIII (Takara, Dalian, China) digested pRN5101 plasmid (Zhang et al. 2018) using the Hieff Clone ${ }^{\mathrm{TM}}$ Multi One Step Cloning Kit (Yeasen, Shanghai, China). The construct was then transferred into E. coli DH5 $\alpha$ competent cells by heat shock. The E. coli DH5 $\alpha$ strain with plasmid pRN5101-Cm was screened on LB agar with $100 \mu \mathrm{g} / \mathrm{mL}$ ampicillin and $5 \mu \mathrm{g} / \mathrm{mL}$ erythromycin. A total of 10 to 15 transformants were verified by PCR with primers $\mathrm{pRN}-\mathrm{F} / \mathrm{pRN}-\mathrm{R}$. The PCR products were sequenced by Shanghai Personal Biological Technology Co., Ltd. (Shanghai, China).

\section{Preparation of competent cells of $P$. polymyxa HY96-2 and electroporation}

The method of preparing the competent cells of $P$. polymyxa HY96-2 was previously described by Zhang et al. (2011) with modifications. The P. polymyxa HY96-2 wild-type strain was activated on an LB plate for $24 \mathrm{~h}$ at $30{ }^{\circ} \mathrm{C}$. A single colony was then inoculated into $50 \mathrm{~mL} \mathrm{LB}$ broth and cultured at 30 ${ }^{\circ} \mathrm{C}$ with shaking at $180 \mathrm{rpm}$ for $18 \mathrm{~h}$. A $500-\mu \mathrm{L}$ aliquot of culture broth of $P$. polymyxa HY96-2 was inoculated into 50 $\mathrm{mL}$ growth medium (LB broth $+0.5 \mathrm{M}$ sorbitol), with shaking at $200 \mathrm{rpm}$ and $30{ }^{\circ} \mathrm{C}$ until $\mathrm{OD}_{600}$ reached $0.6 \sim 0.8$. The culture broth was cooled on ice for $10 \mathrm{~min}$ and then centrifuged at $10,000 \mathrm{rpm}$ for $10 \mathrm{~min}$ at $4{ }^{\circ} \mathrm{C}$ to pellet the bacteria. The bacteria were washed with cooled sterile water one time and washed with cooled ETM buffer ( $0.5 \mathrm{M}$ mannitol, $0.5 \mathrm{M}$ sorbitol, $10 \%$ glycerol) three times (Zhang et al. 2011). The competent cells were then resuspended in $600 \mu \mathrm{L}$ ETM buffer and stored at $-80^{\circ} \mathrm{C}$.

The pRN5101-Cm plasmid ( $2 \mu \mathrm{L}, 120 \mathrm{ng} / \mu \mathrm{L})$ and $P$. polymyxa HY96-2 competent cells $(60 \mu \mathrm{L})$ were mixed on ice. The mixture was transferred into a 1-mm electric shock cuvette and cooled on ice for $10 \mathrm{~min}$. The sample was pulsed with a voltage of $2.2 \mathrm{kV}$ (capacitance of $25 \mu \mathrm{F}$ and a resistance of $200 \Omega$ ) (Gao et al. 2014). After electroporation, $600 \mu \mathrm{L}$ of resuscitation culture medium $(\mathrm{LB}$ medium $+0.5 \mathrm{M}$ sorbitol +
0.38 M mannitol) was added for resuscitation, and the mixture was incubated at $30{ }^{\circ} \mathrm{C}$ with shaking at $180 \mathrm{rpm}$ for $12 \mathrm{~h}$. The mixture was then plated on LB agar with $25 \mu \mathrm{g} / \mathrm{mL}$ chloramphenicol and $5 \mu \mathrm{g} / \mathrm{mL}$ erythromycin and incubated at $30^{\circ} \mathrm{C}$ for $24 \sim 48 \mathrm{~h}$ for selection. Transformants were verified by PCR with primers $\mathrm{pRN}-\mathrm{F} / \mathrm{pRN}-\mathrm{R}$, and PCR products were sequenced.

\section{Screening of luxS gene deletion strain P. polymyxa HY96-2- $\triangle$ luxS}

Electroporated $P$. polymyxa HY96-2 cells with plasmid pRN5101 were cultured for 5 successive generations in LB broth with $25 \mu \mathrm{g} / \mathrm{mL}$ chloramphenicol at $41.5^{\circ} \mathrm{C}$. Cells from the 5 th generation were plated on LB agar with $25 \mu \mathrm{g} / \mathrm{mL}$ chloramphenicol to screen the double crossover recombinants, which were verified by PCR (with primers $l u x S-F / l u x S-\mathrm{R}$ ) and sequencing analysis.

\section{Construction of luxS gene expression vector pMA5-luxS}

The luxS gene was cloned from $P$. polymyxa HY96-2 chromosomal DNA (with primer1121-F/1121-R) and was ligated into pMA5 (Liu and Du 2012) using BamHI and NdeI (Takara, Dalian, China) cleavage sites with the Mut Express® MultiS Fast Mutagenesis Kit V2 (Vazyme, Shanghai, China). The ligation product was transformed into $E$. coli DH5 $\alpha$ cells, which were screened on LB agar with $100 \mu \mathrm{g} / \mathrm{mL}$ ampicillin. Transformants were verified by PCR (with primers TY-F/ TF-R) and sequencing analysis.

\section{Construction of the luxS gene complement strain P. polymyxa HY96-2- $\triangle$ luxS::IuxS}

The competent cells of strain P. polymyxa HY96-2- $\triangle$ lux $S$ were prepared as $P$. polymyxa HY96-2. The pMA5-luxS plasmid was then electroporated into P. polymyxa HY96-2- $\triangle$ luxS competent cells. The electroporated cells were screened on LB agar with $100 \mu \mathrm{g} / \mathrm{mL}$ ampicillin. Transformants were verified by PCR (with primers TY-F/TF-R) and sequencing analysis. The verified positive mutants were the luxS gene complement strain, HY96-2- $\triangle$ lux $S: \because l u x S$.

\section{Construction of luxS gene overexpression strain $P$. polymyxa HY96-2-IuxS}

Plasmid pMA5-luxS was electroporated into $P$. polymyxa HY96-2 competent cells, and the cells were screened on LB agar with $100 \mu \mathrm{g} / \mathrm{mL}$ ampicillin. The verified positive transformants were the luxS gene overexpression strain, P. polymyxa HY96-2-luxS. 


\section{Analysis of the level of luxS gene expression of $P$. polymyxa HY96-2 wild-type strain and its mutants by quantitative PCR}

The RNA extraction of the $P$. polymyxa HY96-2 wild-type strain and its mutants (HY96-2- $\triangle$ luxS, HY96-2- - lux $S:: l u x S$, HY96-2-luxS) was performed using TransZol UP Plus RNA Kit (Tiangen, Beijing, China). Purity and concentration of the RNA were determined using a microplate reader (SynergyMx, BioTek, Winooski, VT, USA). gDNA in total RNA was removed, and cDNA were synthesized using the TransScript One-Step gDNA Removal and cDNA Synthesis SuperMix (TransGen, Beijing, China). Purity and concentration of the cDNA were determined using a microplate reader, and the cDNA were diluted to $50 \mathrm{ng} / \mathrm{uL}$ with double-distilled $\mathrm{H}_{2} \mathrm{O}$. Quantitative PCR (qPCR) experiments were performed using TransStart Top Green qPCR SuperMix (TransGen, Beijing, China) in $20 \mu \mathrm{L}$ final volumes. PCR mixtures were prepared in nuclease-free water and contained $1 \times$ TransStart Top Green qPCR SuperMix, $0.2 \mu \mathrm{M}$ of each primer (DLluxS-F/ DLluxS$\mathrm{R})$, and $50 \mathrm{ng}$ of cDNA template. The $16 \mathrm{~S}$ rRNA was selected as the reference gene, and the primers used were $27 \mathrm{~F} / 1492 \mathrm{R}$ (Supplementary Table S2). Amplifications were performed using a BIO-RAD CFX-96 real-time PCR system (Hercules, CA, USA) with the following thermal cycling protocol: $95{ }^{\circ} \mathrm{C}$ for $5 \mathrm{~min} ;\left(95{ }^{\circ} \mathrm{C}\right.$ for $10 \mathrm{~s}, 56{ }^{\circ} \mathrm{C}$ for 10 s, $72{ }^{\circ} \mathrm{C}$ for $\left.30 \mathrm{~s}\right) \times 40$ cycles and $72{ }^{\circ} \mathrm{C}$ for $5 \mathrm{~min}$. Relative transcript abundance was calculated using the $\Delta \Delta \mathrm{Ct}$ method. The transcription of a given gene was calculated as the difference in qPCR threshold cycles $(\mathrm{Ct})$. As one PCR cycle represents a twofold difference in template abundance, fold change values were calculated as $2^{-\Delta \Delta \mathrm{Ct}}$. Three independent experiments were performed.

\section{Assay for biofilm formation in vitro}

The P. polymyxa HY96-2 wild-type strain and its mutants were cultured in $\mathrm{LB}$ broth until $\mathrm{OD}_{600}$ reached 0.8. Aliquots of the different cell cultures $(50 \mu \mathrm{L})$ were inoculated into 10 $\mathrm{mL}$ glass tubes with $5 \mathrm{~mL} \mathrm{LB}$ broth and incubated unshaken at $30^{\circ} \mathrm{C}$ for 2 to 8 days. After incubation, the cultured broth was carefully withdrawn and the test tubes were washed twice with sterile water. One milliliter of $1 \%(\mathrm{w} / \mathrm{v})$ crystal violet was added to the test tubes and rolled in the test tubes to stain all biofilm. The test tubes were allowed to stand for $15 \mathrm{~min}$ at room temperature, and then, the solution was withdrawn and the test tubes were carefully washed five times with sterile water. Subsequently, $2.5 \mathrm{~mL}$ of acetone-ethanol $(20: 80, \mathrm{v} / \mathrm{v})$ was added to dissolve the crystal violet binding to the biofilm (Yegorenkova et al. 2011). The absorbance $\left(\mathrm{A}_{590}\right)$ of the solution was determined by a microplate reader (SynergyMx, BioTek, Winooski, VT, USA).

\section{Assay for biofilm formation in vivo}

A total of $20 \mathrm{~mL}$ of cultured broth of the P. polymyxa HY96-2 wild-type strain and its mutants were poured into sterile plates. Tomato seedlings with heights of approximately $10 \mathrm{~cm}$ were pulled out of the sterilized soil, and their roots were washed with sterile water. The seedlings were then incubated in cell cultures of the HY96-2 wild-type strain and its mutants for 1 $\mathrm{h}$; seedlings treated with sterile LB broth served as the control group. The treated plants were transferred to sterile nutrient solution and grown in a plant growth chamber (MGC-400, Yiheng, Shanghai, China) at $28^{\circ} \mathrm{C}$ with a 16 -h light regime. For the analysis, root segments with the length of $0.4 \sim 1 \mathrm{~cm}$ (Ren et al. 2012) were obtained and stored at $-80^{\circ} \mathrm{C}$ after 2 , 5 , and 8 days of incubation. The root segments were immobilized at room temperature with $2.5 \%$ glutaraldehyde (preparation with $0.1 \mathrm{~mol} / \mathrm{L}$ phosphate buffer) for $6 \mathrm{~h}$. After that, the treated roots were washed 3 times with $0.1 \mathrm{~mol} / \mathrm{L}$ phosphate buffer ( $\mathrm{pH}$ 7.2) for $15 \mathrm{~min}$ (Thokchom et al. 2017). The treated samples were adhered to the sample table using a conductive adhesive. The colonization and biofilm formation of each strain on the roots of tomato plants were observed by cryo-scanning electron microscopy (S-3400N, Hitachi, Tokyo, Japan).

\section{Biocontrol efficacy of $P$. polymyxa HY96-2 wild-type strain and its mutants against $R$. solanacearum}

Tomato seeds were sown in sterilized soil, and the seedlings with 3 to 4 leaves were transplanted into individual $10-\mathrm{cm}$ pots 3 weeks later. Seedlings were cultivated under sufficient light and water in a greenhouse. The greenhouse experiment was carried out when the tomato seedlings grew to about $20 \mathrm{~cm}$ in height (at the 5 to 6 leaves stage of the seedlings, 8 to 10 days after transplanting), and six treatments were designed as follows: treatment 1 , treated with water only (CK1); treatment 2, treated with $R$. solanacearum only (CK2); treatment 3, treated with P. polymyxa HY96-2 first and $R$. solanacearum later; treatment 4 , treated with $P$. polymyxa HY96-2- $\triangle l u x S$ first and $R$. solanacearum later; treatment 5, treated with P. polymyxa HY96-2-luxS first and $R$. solanacearum later; and treatment 6 , treated with P. polymyxa HY96-2- $\triangle l u x S:: l u x S$ first and $R$. solanacearum later. On the 1st day of the experiment, the P. polymyxa HY962 WT or mutants were inoculated to the rhizosphere of the seedlings of treatment 3 to treatment 6 , as well as treatment 1 and 2 just drenched with the same amount of water. On the 3 rd day, the soil pathogen, $R$. solanacearum, was inoculated to the rhizosphere of the seedlings of all treatments except treatment 1 . The drench dosages of P. polymyxa HY96-2 and $R$. solanacearum were $50 \mathrm{~mL}$ at $10^{7} \mathrm{CFU} / \mathrm{mL}$. There were three biological replicates per treatment and 10 plants per replicate. The plants were incubated at $28 \pm 1{ }^{\circ} \mathrm{C}$ in a greenhouse 
with relative humidity of $70 \%$ during the greenhouse experiment. The disease severity and control efficacy of each treatment were recorded and calculated on the 8th, 13th, and 18th day $(5,10$, and 15 days after inoculation of $R$. solanacearum). The experiment was stopped when disease incidence reached $60 \%$ in CK2 (about at the 8 to 9 leaves stage of the seedlings).

The disease index (DI) was scored on the following 0-9 scale: 0 , no visible symptoms; 1 , one branch wilted at the top; 3 , two branches wilted at the top; 5 , three to four branches wilted; 7, only one branch is healthy; and 9, death of plant. The disease incidence, disease severity (DS), and biocontrol efficacy (BE) were calculated according to Li et al. (2017) and Wang et al. (2019) as follows:

$D_{1}=\frac{N_{\mathrm{I}}}{N} \times 100 \%$

where $D_{1}$ is the disease incidence, $N_{\mathrm{I}}$ is the number of infected plants, and $N$ is the total number of treated plants,

$\mathrm{DS}=\frac{\sum\left(N_{\mathrm{i}} \times \mathrm{DI}\right)}{N_{\mathrm{d}} \times 9} \times 100 \%$

where $N_{\mathrm{i}}$ is the number of diseased plants of the corresponding disease index (DI), $N_{\mathrm{d}}$ is the total number of plants investigated, and the DI was recorded based on a scale of $0 \sim 9$,

$\mathrm{BE}=\frac{\mathrm{DS}_{\mathrm{CK}}-\mathrm{DS}_{\mathrm{T}}}{\mathrm{DS}_{\mathrm{CK}}} \times 100 \%$

where $\mathrm{DS}_{\mathrm{CK}}$ is the disease severity of $\mathrm{CK} 2$ and $\mathrm{DS}_{\mathrm{T}}$ is the disease severity of plants treated with $P$. polymyxa HY96-2 wilt-type strain and its mutants.

\section{Statistical analyses}

A minimum of three independent biological replicates were performed in all experiments. One-way analysis of variance (ANOVA) was carried out with SPSS (version 22.0, IBM, Armonk, NY, USA) and Dunnett's multiple range test $(P \leq 0.05)$ for statistical analysis of all data.

\section{Results}

\section{Construction and verification of $P$. polymyxa HY96-2 mutants}

Using homologous recombination, the luxS gene of $P$. polymyxa HY96-2 was replaced by a chloramphenicol resistance gene cassette to construct a lux $S$ gene deletion strain (Fig. 1a). Then, the deletion mutant P. polymyxa HY96-2- $\triangle$ luxS obtained by electroporation with deletion plasmid pRN5101-Cm was verified by PCR (Fig. 1b). Furthermore, the luxS gene complement mutant, P. polymyxa HY96-2- $\triangle$ luxS::luxS (Fig. 2a), and luxS gene overexpression mutant, P. polymyxa HY96-2-luxS (Fig. 2b), obtained by electroporation with plasmid pMA5-luxS were verified by PCR. All plasmids and mutants were verified by PCR using genome-specific primers, and the PCR products were sequenced for further verification.

The expression levels of the luxS gene of the P. polymyxa HY96-2 wild-type strain and its mutants were compared by qPCR. The results (Fig. 3) showed that the luxS gene of $P$. polymyxa HY96-2- $\triangle$ luxS lacked significant expression, and the expression of the luxS gene from the complement strain P. polymyxa HY96-2- $\triangle$ luxS: :luxS was 21.36-fold higher than that of the wild-type strain. The expression of the luxS gene from the overexpression strain P. polymyxa HY96-2-luxS was 358.27-fold higher than that of the wild-type strain.

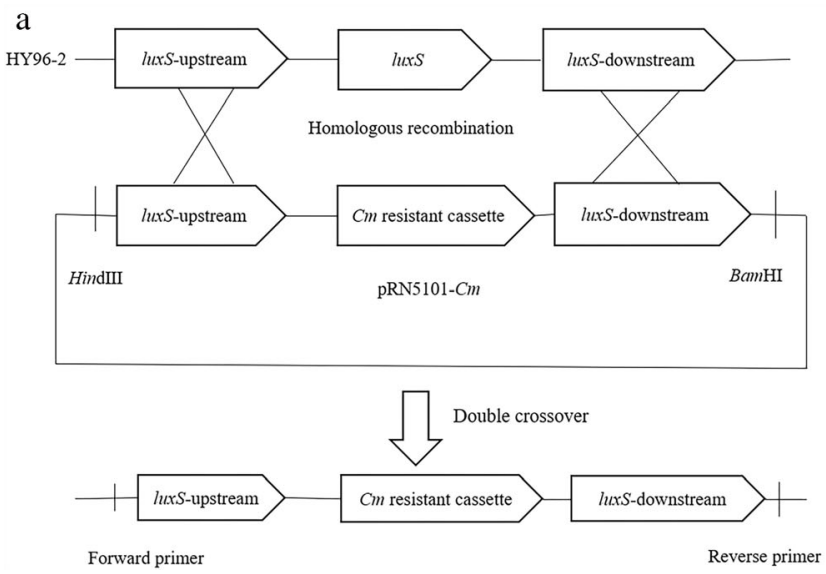

b

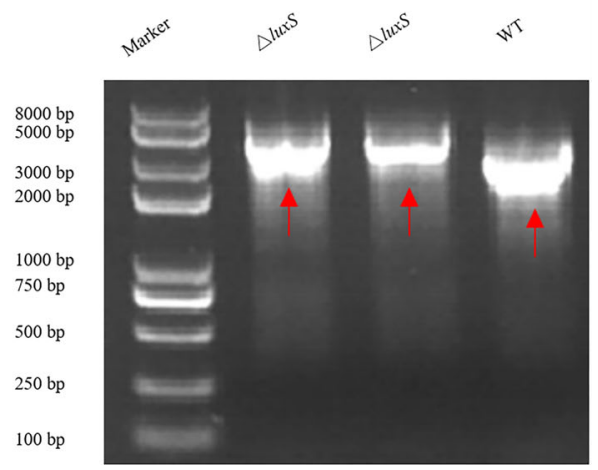

Fig. 1 The construction of deletion mutants P. polymyxa HY96-2- $\triangle$ luxS. a A schematic diagram of double crossover recombinants obtained by homologous recombination. $\mathrm{Cm}$, chloramphenicol. $\mathbf{b} \mathrm{PCR}$ verification of the construction of deletion mutants P. polymyxa HY96-2- $\triangle$ luxS. The red

arrows point to fragments cloned from transformants HY96-2- $\triangle$ luxS and HY96-2 wild-type strain with primers $l u x S-F$ and $l u x S$-R. The sizes of the bands cloned from HY96-2- $\triangle l u x S$ are $3770 \mathrm{bp}$, and the sizes of that from HY96-2 wild-type strain are 2967 bp 

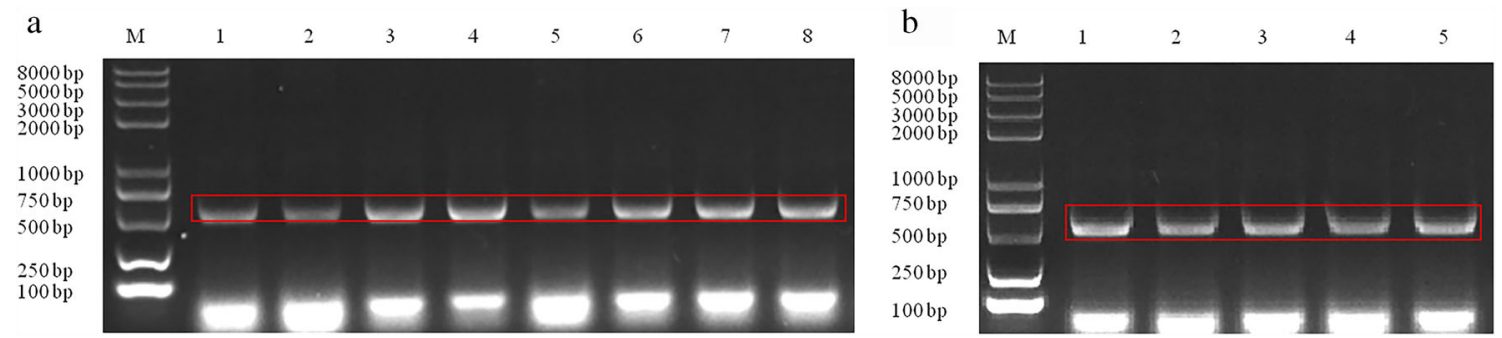

Fig. 2 PCR verification of the construction of $l u x S$ complement mutants and overexpression mutants of $P$. polymyxa HY96-2. a PCR verification of the construction of complement mutants P. polymyxa HY96-2$\triangle$ lux $S: \because$ lux $S$. M, DNA marker; 1-8, PCR amplification of the luxS gene in positive transformants with primers TY-F and TY-R; the size of the expected bands is about $562 \mathrm{bp}$. b PCR verification of the construction of overexpression mutants $P$. polymyxa HY96-2-luxS. M, DNA marker; 15; PCR amplification of the luxS gene in positive transformants with primers TY-F and TY-R; the size of the bands is about $562 \mathrm{bp}$

\section{The luxS gene positively regulated the biofilm formation of $P$. polymyxa HY96-2 in vitro}

An assay of biofilm formation in vitro was performed in glass tubes. It was found that the biofilm of the P. polymyxa HY96-2 wild-type strain was visible to the naked eye on the 2nd day after inoculation, and the biomass of the biofilm reached its maximum on the 5 th day. The biofilm began to degrade on the 8th day, but the undegraded biofilm was stable for at least 20 days after inoculation (Supplementary Fig. S1). Therefore, the biofilm formation ability of the HY96-2 wild-type and its mutants was determined by crystal violet staining on the 2nd, 5th, and 8th day after inoculation. On the 2nd day after inoculation, compared with the wild-type P. polymyxa HY962 strain, the biofilm formation ability of the $P$. polymyxa

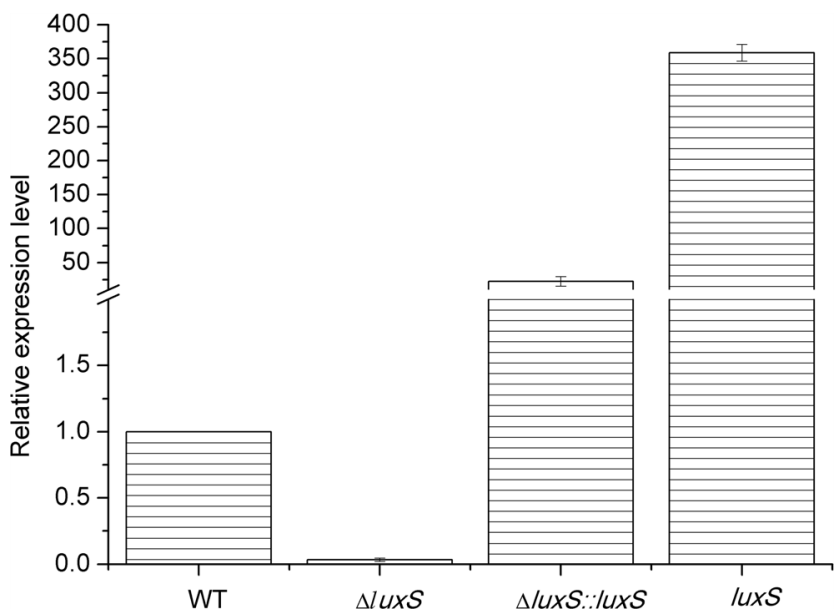

Fig. 3 Analysis of the luxS gene expression level of P. polymyxa HY96-2 wild-type strain and its mutants by qPCR. All data represented the mean value of triplicate trials. WT, wild-type strain; $\triangle l u x S$, $l u x S$ deletion strain; $\operatorname{lu} x S$, luxS overexpression strain; $\triangle \operatorname{luxS}:$ : luxS, luxS complement strain. P. polymyxa HY96-2 wild-type strain was inoculated in LB broth, P. polymyxa HY96-2- $\triangle$ luxS was inoculated in LB broth with $25 \mu \mathrm{g} / \mathrm{mL}$ chloramphenicol, $P$. polymyxa HY96-2- $\Delta$ luxS::luxS and $P$. polymyxa HY96-2-luxS were inoculated in LB broth with 100 $\mu \mathrm{g} / \mathrm{mL}$ ampicillin, and all of the stains were cultured at $30{ }^{\circ} \mathrm{C}$ with shaking at $180 \mathrm{rpm}$ for $18 \mathrm{~h}$
HY96-2- $\triangle$ luxS strain decreased by $29.27 \%$, and the biofilm formation ability of the $P$. polymyxa HY96-2-luxS, as well as the P. polymyxa HY96-2- $\triangle$ luxS::luxS strains, increased by $23.23 \%$ and $20.24 \%$, respectively (Fig. 4). On the 5th day after inoculation, compared with the wild-type $P$. polymyxa HY96-2 strain, the biofilm-forming ability of the P. polymyxa HY96-2- $\triangle$ luxS strain decreased by $30.35 \%$, and the biofilm formation ability of the P. polymyxa HY96-2-luxS strain increased by $27.46 \%$, while the biofilm formation ability of the P. polymyxa HY96-2- $\triangle$ luxS: :luxS strain showed no significant difference between that of the wild-type P. polymyxa HY96-2 strain (Fig. 4). On the 8th day after inoculation, compared with the wild-type P. polymyxa HY96-2 strain, the biofilm formation ability of

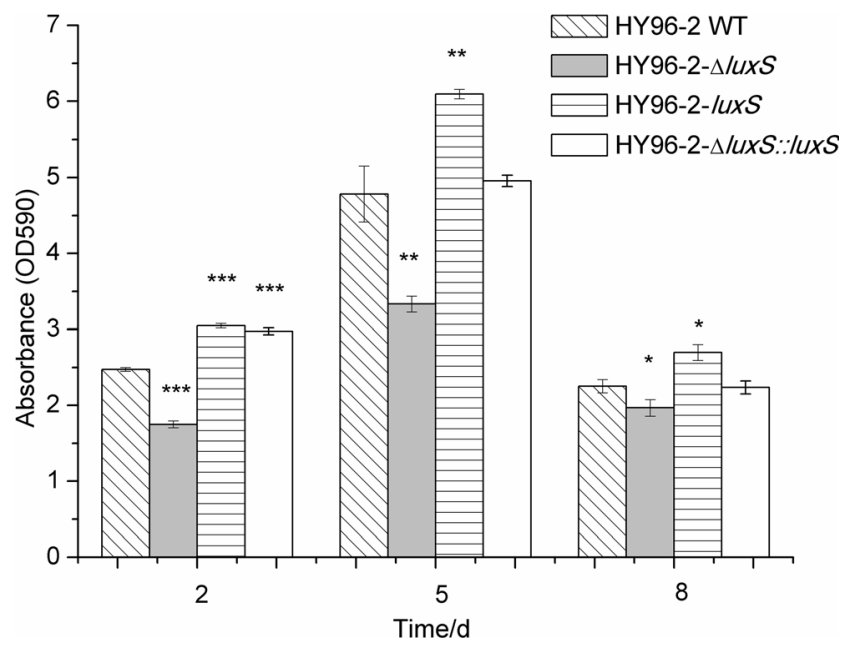

Fig. 4 Assay for biofilm formation by $P$. polymyxa HY96-2 wild-type strain and its mutants in vitro. P. polymyxa HY96-2 wild-type strain was inoculated in LB broth, P. polymyxa HY96-2- $\triangle$ lux $S$ was inoculated in LB broth with $25 \mu \mathrm{g} / \mathrm{mL}$ chloramphenicol, P. polymyxa HY96-2- $\triangle$ lux $S:: l u x S$ and P. polymyxa HY96-2-luxS were inoculated in LB broth with $100 \mu \mathrm{g} /$ $\mathrm{mL}$ ampicillin, and all of the stains were cultured unshaken at $30^{\circ} \mathrm{C}$. The biofilms were investigated at the 2nd, 5th, and 8th day postinoculation. One asterisk $(*)$, two asterisks $(* *)$, and three asterisks $(* * *)$ indicate significant difference between the treatments for a given time at $P<$ $0.05, P<0.01$, and $P<0.001$, respectively. All data represented the mean value of triplicate trials 
the P. polymyxa HY96-2- $\Delta$ luxS strain decreased by $12.61 \%$, and the biofilm formation ability of the P. polymyxa HY96-2luxS strain increased by $19.75 \%$, while the biofilm formation ability of the P. polymyxa HY96-2- - lux $S:: l u x S$ strain still showed no significant difference between that of the wildtype P. polymyxa HY96-2 stain (Fig. 4). The images of biofilm stained by crystal violet also showed similar results (Supplementary Fig. S2). These results indicated that the deletion of luxS significantly reduced the biofilm formation ability of P. polymyxa HY96-2, while overexpression of luxS significantly improved its biofilm formation ability, and the complement of lux $S$ gene could also significantly rescue its biofilm formation ability. Therefore, the AI-2 QS system regulated by luxS played an important role in biofilm formation of $P$. polymyxa HY96-2 in vitro, and luxS positively regulated the biofilm formation of this strain in vitro.

\section{The luxS gene positively regulated the biofilm formation of $P$. polymyxa HY96-2 in vivo}

The investigation of the colonization and biofilm formation of the P. polymyxa HY96-2 wild-type strain and its mutants on the roots of tomato plants was performed using cryo-SEM. The results showed that on the 2nd day after inoculation, HY96-2- $\triangle l u x S$ had no obvious biofilm detected, while other strains began to form biofilms. The ability to colonize and form biofilm on the roots of tomato seedlings decreased in the strain order: $P$. polymyxa HY96-2-luxS $>$ P. polymyxa HY96-2 wild-type $\approx$ P. polymyxa HY96-2- $\triangle$ luxS: :luxS (Fig. 5a). On the 5th day after inoculation, more biofilm was formed and more bacteria were wrapped in them in all strains. The biofilm formed by strain P. polymyxa HY96-2- $\triangle$ luxS was reduced compared to that of the wild-type strain, while the biofilm formed by the $P$. polymyxa HY96-2-luxS and P. polymyxa HY962- $\triangle$ lux $:: \operatorname{lux} S$ strains was increased compared to that of the wild-type strain, and the amount of biofilm formed by strain P. polymyxa HY96-2-luxS was higher than that of strain $P$. polymyxa HY96-2- $\triangle$ luxS: :luxS (Fig. 5b). Few bacteria or biofilms from any of the strains were observed on the 8th day after inoculation (Fig. 5c). These results suggested that the deletion of luxS reduced the colonization and biofilm formation ability of P. polymyxa HY96-2 on tomato roots, and the overexpression of luxS promoted these abilities; the complement of luxS could restore these abilities to at least levels similar to that of wild-type strain. These conclusions were consistent with the results observed in vitro. Therefore, the AI-2 QS system regulated by luxS also played an important role in the colonization and biofilm formation of $P$. polymyxa HY96-2 in vivo, and luxS also positively regulated the biofilm formation in vivo.

\section{The luxS gene positively regulated the biocontrol efficacy against $R$. solanacearum by $P$. polymyxa HY96-2}

The results of the greenhouse experiments (Table 2) showed that the biocontrol efficacies of all treatments decreased with the increase of disease severity of CK2 (inoculated with $R$. solanacearum only) from the early stage (5 days after inoculation, the disease incidence of CK2 was $25.26 \%$ ) to the late stage ( 15 days after inoculation, the disease incidence of CK2 was $61.35 \%$ ) of tomato bacterial wilt. The biocontrol efficacy of strain $P$. polymyxa HY96-2- $\triangle$ luxS was the lowest during the whole test period, with $66.54 \pm 5.31 \%$ in the early stage and $50.70 \pm 1.39 \%$ in the late stage. These levels were significantly lower than that of wild-type strain with $82.37 \pm$ $1.70 \%$ in the early stage and $65.94 \pm 2.73 \%$ in the late stage. The biocontrol efficacy of strain P. polymyxa HY96-2-luxS was the highest during the whole test period with $100 \pm$ $0.00 \%$ in the early stage and $75.66 \pm 1.94 \%$ in the late stage, which was significantly higher than that of wild-type strain at the same disease stages. The biocontrol efficacy of strain P. polymyxa HY96-2- $\triangle$ luxS: :luxS was similar to that of P. polymyxa HY96-2-luxS in the early stage of tomato bacterial wilt and similar to those of the wild-type strain at the peak and late stage of tomato bacterial wilt. These results indicated that the deletion of lux $S$ significantly decreased the biocontrol efficacy against tomato bacterial wilt by $P$. polymyxa HY96-2, and the overexpression of luxS increased its biocontrol efficacy. The complement of luxS restored the biocontrol ability of the luxS deletion strain, P. polymyxa HY96-2- $\triangle$ lux $S$, to the level of wild-type strain or above. Therefore, the AI-2/luxS QS system played an important role in the biocontrol efficacy against tomato bacterial wilt in P. polymyxa HY96-2, and luxS positively regulated the biocontrol efficacy of the strain.

\section{Discussion}

It has been reported that the $\operatorname{lux} S$ gene, which is a key regulatory gene of the AI-2-mediated quorum sensing (QS) system, affected the biomass and morphology of biofilms formed by some bacterial species. For some species, luxS expression positively regulated their biofilm formation. These species (Table 1) included Gram-negative human pathogens Haemophilus influenzae (Armbruster et al. 2009) and Capnocytophaga ochracea (Hosohama-Saito et al. 2016), Gram-positive human pathogens S. mutans (Yoshida et al. 2005) and S. pneumoniae (Vidal et al. 2011), Gram-positive animal pathogens Streptococcus suis (Wang et al. 2011), and Gram-positive human probiotics B. longum (Sun et al. 2014), Bifidobacterium breve (Christiaen et al. 2014), and B. subtilis, which is a contaminant bacterium in the dairy industry (Duanis-Assaf et al. 2015). However, luxS negatively 

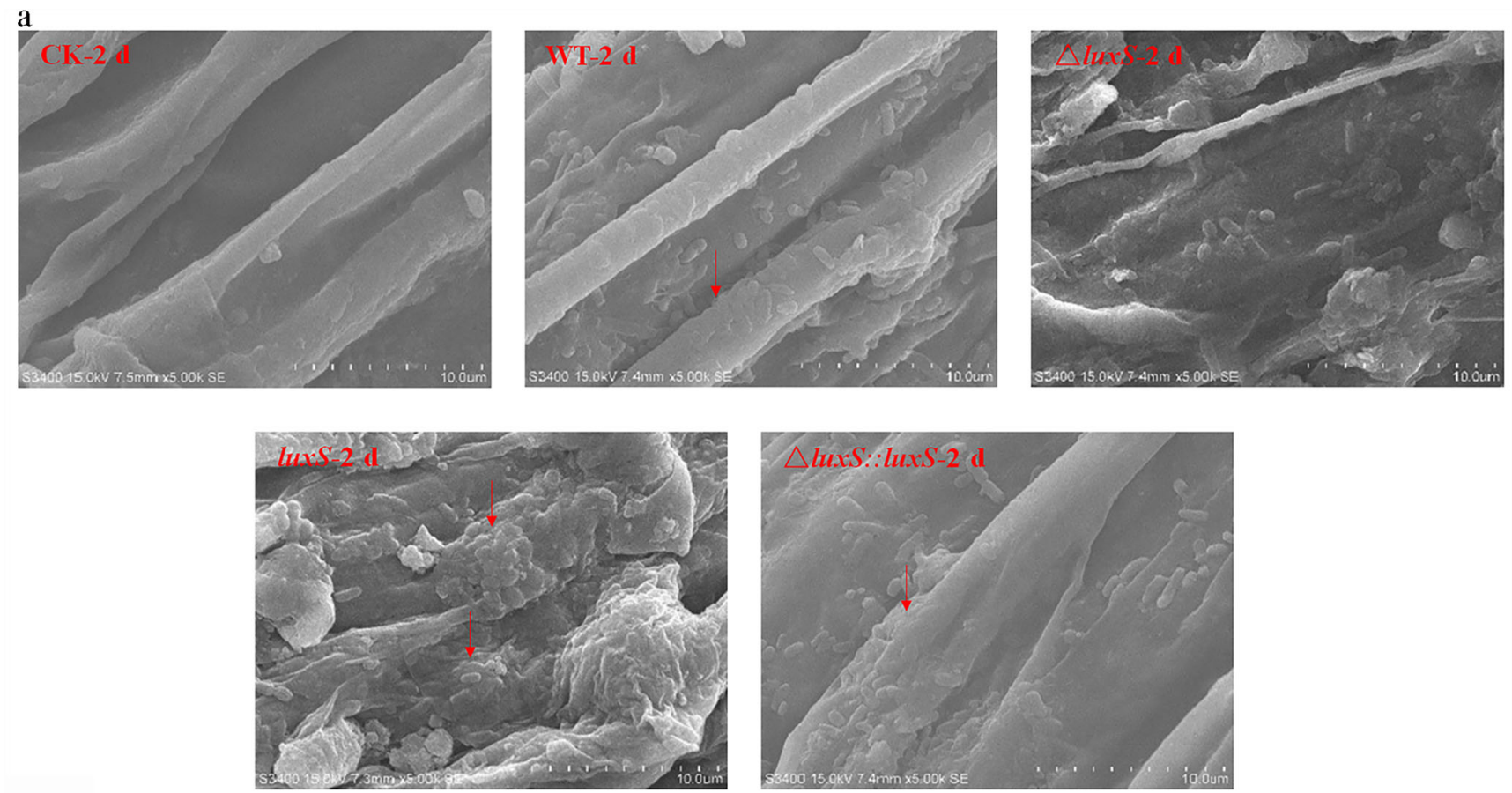

b
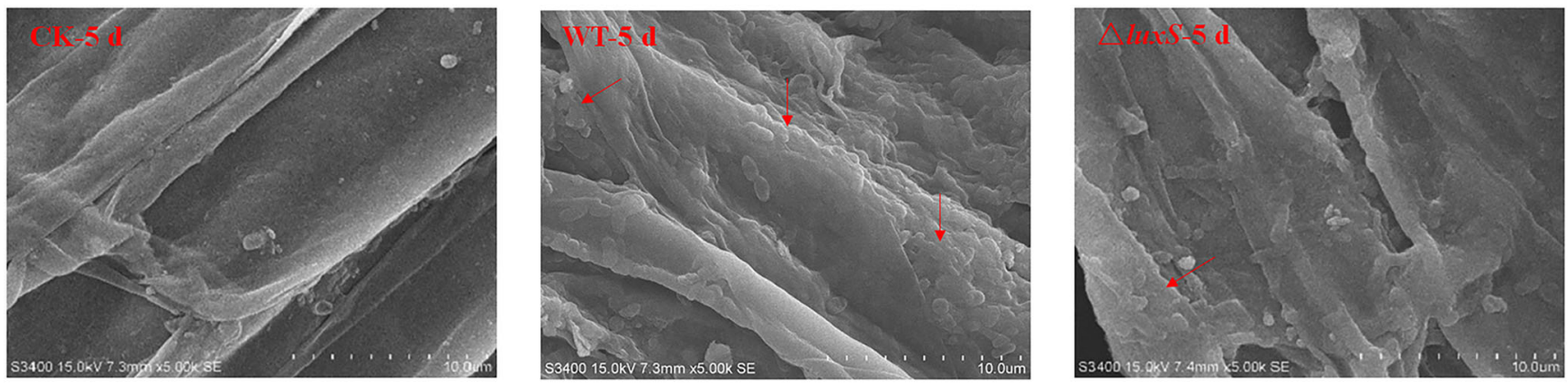

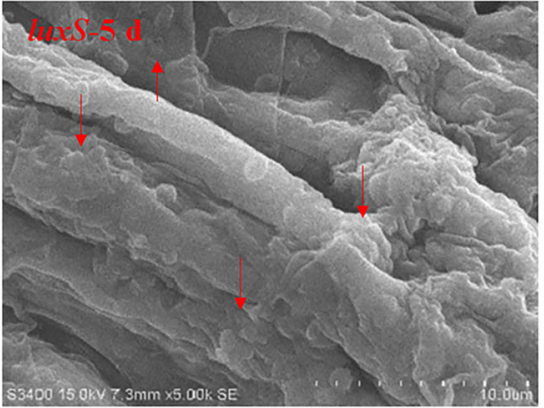

Fig. 5 The biofilm formation by $P$. polymyxa HY96-2 wild-type strain and its mutants on the roots of tomato plants was observed by cryo-SEM at $\mathbf{a} 2$ days, b 5 days, and $\mathbf{c} 8$ days after inoculation. The red arrows indicate the spots where the HY96-2 cells aggregated obviously and

regulated the biofilm formation in other species (Table 1), including the Gram-positive human pathogens $S$. aureus (Ma et al. 2017a), Staphylococcus epidermidis (Xu et al. 2006a), Listeria monocytogenes (Sela et al. 2006), and B. cereus (Auger et al. 2006). In addition, luxS also showed marked differences in biofilm structure between the wild-type

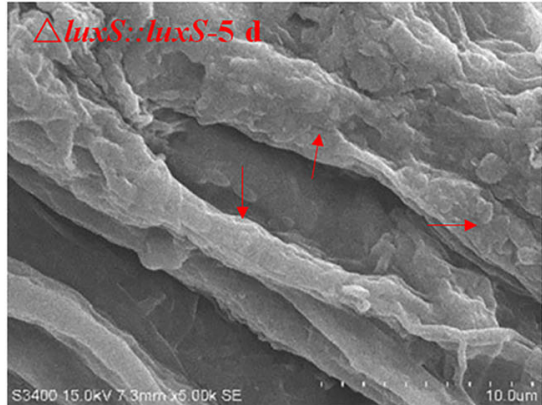

formed the biofilm. CK, control; WT, wild-type strain; $\triangle l u x S$, lux $S$ deletion strain; luxS, luxS overexpression strain; $\triangle$ lux $S:: l u x S$, lux $S$ complement strain. All experiments were performed in triplicate, and a representative result was shown

strain and the luxS mutants in $S$. mutans. The luxS deletion strain of $S$. mutans adopted a much more granular biofilm, rather than the relatively smooth biofilm seen in the wildtype strain (Merritt et al. 2003). The biofilm of the S. suis wild-type strain was multi-layered with more extracellular matrix, but the biofilm formed by the luxS deletion strain 
C
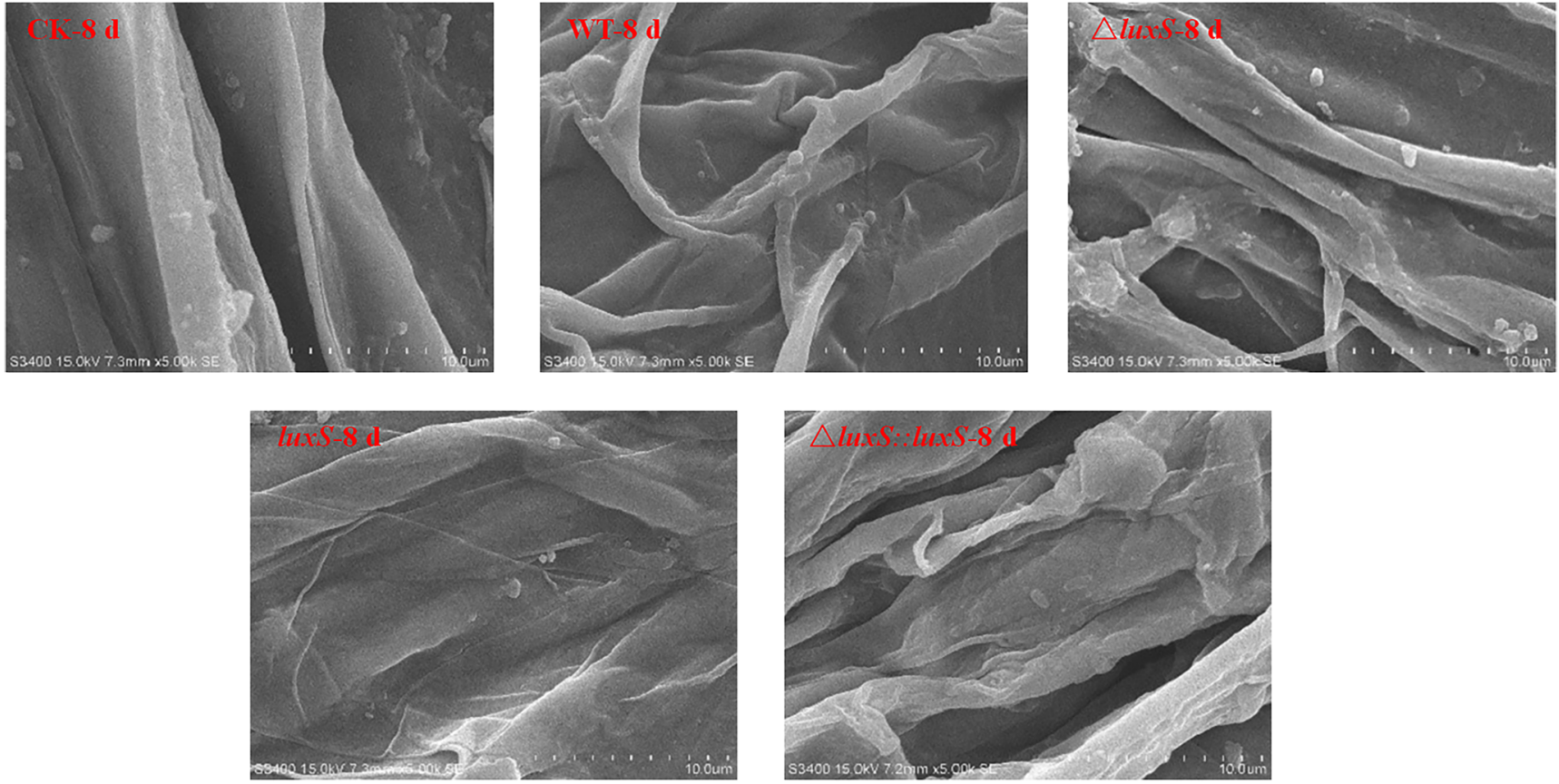

Fig. 5 (continued)

was less dense with less extracellular matrix (Wang et al. 2011). The luxS deletion strain of S. epidermidis generated a more compact and thicker biofilm than that of the wild-type strain (Xu et al. 2006a).

The impact of $\operatorname{luxS}$ on the biofilm formation varies for different species of Bacillus, which might be related to the different regulatory mechanisms of luxS in different Bacillus species. luxS positively regulated the biofilm formation of B. subtilis NCIB3610, which is a contaminant bacterium in the dairy industry (Table 1). Duanis-Assaf et al. (2015) found that lactose, the primary sugar in milk, might induce the biofilm formation of $B$. subtilis by promoting the expression of the tapA and epsA-O operons, which are responsible for biofilm matrix production. In this case, it seemed that lactose enhanced the production of AI-2 rather than the biofilm formation cascade (Duanis-Assaf et al. 2015). The activation of biofilm formation via the QS system might be an additional regulatory mechanism which enabled fine tuning of the biofilm formation pathway (Duanis-Assaf et al. 2015). On the contrary, luxS negatively regulated the biofilm formation of $B$. cereus, which is a causative agent of food-borne diseases (Table 1). Auger et al. (2006) found that the regulatory mechanism of $l u x S$ on biofilm formation might be related to the $l s r$-like genes in $B$. cereus ATCC 10987. The Lsr-like system could be responsible for AI2 uptake and processing (Auger et al. 2006). It was worth noting that the Lsr-like system was recently found in Gramnegative bacteria, such as Salmonella typhimurium and E. coli, but not in any other sequenced Gram-positive bacteria, including B. subtilis, Bacillus halodurans, or Listeria spp. (except B. cereus) (Auger et al. 2006).
As a biocontrol agent, $P$. polymyxa formed biofilms around the roots of plants (Timmusk et al. 2005; Yegorenkova et al. 2013) and $l u x S$ was reported as the key regulatory gene in its QS system (Luo et al. 2018). However, there have been no reports to date on luxS regulating the biofilm formation of biocontrol agents, including P. polymyxa. Therefore, in this study, the effect of luxS on biofilm formation of $P$. polymyxa HY96-2 wild type and its luxS mutants, $P$. polymyxa HY96-

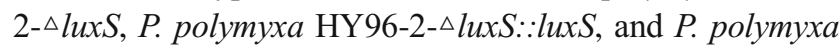
HY96-2-luxS, was reported. The results in vitro and in vivo showed that the deletion of luxS significantly reduced the biofilm formation ability of strain HY96-2, while overexpression of luxS significantly improved its biofilm formation ability and the complement of luxS gene restored its biofilm formation ability. In addition, $\operatorname{lux} S$ did not change the morphology of the biofilm formed by P. polymyxa HY96-2. Both the wildtype strain and the luxS mutants of $P$. polymyxa HY96-2 formed white and viscous biofilms on the wall of test tubes and smooth and transparent biofilms on the roots of tomato plants.

Among Bacillus, the relatively clear biofilm formation pathways of B. subtilis have been reported, and these pathways mainly included the Spo0A regulatory pathway, the SlrR-SinR epigenetic switch, and the DegS-DegU two-component system (Vlamakis et al. 2013). B. cereus was also reported to have a regulation of biofilm formation through the Spo0A pathway (Xu et al. 2017). Our previous study showed that the possible pathways of biofilm formation in $P$. polymyxa included the Spo0A regulatory pathway and the DegS-DegU pathway (Luo et al. 2018). However, slight 
differences between the Spo0A regulatory pathways of $P$. polymyxa and B. subtilis were detected. Compared with B. subtilis, P. polymyxa lacked a mediator Spo0B, which transferred the phosphate group from Spo0F to Spo0A (Luo et al. 2018). Considering the completely different regulatory mechanisms of $l u x S$ on the biofilm formation of $B$. subtilis and $B$. cereus (Table 1), as well as the differences between $P$. polymyxa and B. subtilis in biofilm formation pathways, the question of whether the mechanism of luxS affecting biofilm formation in P. polymyxa HY96-2 is the same as that in B. subtilis requires further study.

In the evaluation of the biofilm formation ability in vivo, 8 days after inoculation, there were few biofilms detected in the treatment of $P$. polymyxa HY96-2 wild-type or in the other treatments of its mutants. It was speculated that this might be due to the fact that tomato seedlings were cultured in liquid soilless culture with limited nutrition. On the 8th day, due to insufficient nutrition, the growth of tomato seedlings was weak, the bacteria attached to its roots were not provided sufficient nutrition, and the biofilm of the strains began to degrade. The bacteria then broke away from the root of the tomato seedlings with the degradation of unstable biofilm. Similarly, the colonization investigation of P. polymyxa C5 on tobacco roots also showed that the cell density began to decrease 9 days after inoculation (Ren et al. 2012). However, the cell density in that study seemed to have decreased less than that of $P$. polymyxa HY96-2 because tobacco plants were cultured in plastic cups with $300 \mathrm{~g}$ of soil, which provided more nutrition.

Biofilms are a microbial community attached to the surface of an object (Mah and O'Toole 2001; O'Toole et al. 2000). Microorganisms in biofilms live in their own extracellular polymers (EPS), which are mainly composed of polysaccharides, proteins, nucleic acids, and lipids (Flemming and Wingender 2010). Previous studies have shown that biofilms formed by some biocontrol agents could facilitate their biocontrol efficacy especially against the soil-borne diseases. Bais et al. (2004) reported that biocontrol of B. subtilis against infection of Arabidopsis roots by Pseudomonas syringae was facilitated by biofilm formation. Klein and Kupper (2018) found that biofilm formed by the fungus Aureobasidium pullulans ACBL-77 enhanced the ability of biocontrol efficacy against sour rot in citrus. The biofilm formation by P. polymyxa also showed a significant impact on the improvement of biocontrol efficacy. Timmusk et al. (2009) reported that $P$. polymyxa strains with better biofilm formation ability had higher biocontrol efficacy against Phytophthora palmivora and Pythium aphanidermatum in Arabidopsis thaliana. Haggag and Timmusk (2010) found that colonization of peanut roots by the biofilm-forming strain $P$. polymyxa initiated biocontrol against crown rot disease. Ren et al. (2012) suggested that biofilm formation of the P. polymyxa C5 strain in tobacco roots is one of the mechanisms used to 
protect tobacco from fungal infection. It has long been considered that the function of biofilm formation of biocontrol agents is to resist pathogens invading plant roots and restricts colonization sites and nutrition in the rhizosphere of plants; the impact of this is to limit the population of the pathogens and control disease (Bais et al. 2004). The latest research of Timmusk et al. (2019) showed that the P. polymyxa A26 antagonistic activity against Fusarium Head Blight caused by Fusarium graminearum was positively correlated with Dglucuronate content (and not a common non-ribosomal antibiotic lipopeptide) in biofilm extracellular polysaccharides. P. polymyxa HY96-2 effectively resisted the invasion of $R$. solanacearum, as was verified by our previous studies (Xu et al. 2006b). However, further studies are needed to determine whether the biofilm matrix of $P$. polymyxa HY962 contains some substance which can inhibit the growth of pathogenic bacteria and improve its biocontrol efficacy against bacterial wilt.

It has been reported that luxS, a key regulator of AI-2 QS, can affect the virulence or biocontrol efficacy of the strains by affecting their biofilm formation abilities. For example, the luxS deletion mutant of $E$. coli 107/86 exhibited reduced biofilm formation and decreased pathogenicity (Yang et al. 2014). The luxS deletion mutant of $B$. breve UCC2003 showed decreased colonization ability in the intestinal tract of mice and Caenorhabditis elegans, which resulted in a worsened effect on preventing C. elegans from being infected by Salmonella than that of the wild-type strain (Christiaen et al. 2014). At present, there is no reported research about how lux $S$ affects the biocontrol efficacy of biocontrol agents, including P. polymyxa. However, other QS systems have been suggested to regulate biofilm formation and affect biocontrol efficacy in Gram-negative biocontrol agents. The PcoI-PcoR QS system (LuxR-LuxI family) found in Pseudomonas fluorescens 2P24 showed a significant effect on its biofilm formation and biocontrol efficacy. The $p c o I$ deletion mutant of strain 2P24 significantly reduced the biofilm formation, as well as colonization, on wheat rhizosphere, and then affected its biocontrol ability against wheat take-all (Wei and Zhang 2006).

In this study, the effect of luxS on biocontrol efficacy against $R$. solanacearum by $P$. polymyxa was investigated with P. polymyxa HY96-2 wild-type and its mutants. The results (Table 2 ) indicated that luxS positively regulated the biocontrol efficacy of strain HY96-2. In P. polymyxa HY96-2, the impact of $\operatorname{lux} S$ on biofilm formation was consistent with its effect on biocontrol efficacy against $R$. solanacearum. Therefore, we concluded that $l u x S$ improved the biocontrol efficacy of $P$. polymyxa HY96-2 by promoting its biofilm formation ability. More biofilm was formed by the overexpression strain, P. polymyxa HY96-2-luxS, and encapsulated more bacteria in it, which occupied more physiological sites on the roots of tomato plants to prevent the invasion of
$R$. solanacearum. On the other hand, more cells of strain HY96-2 located in the rhizosphere of tomato plant would consume more nutrients, so less nutrition would be available for $R$. solanacearum, which would limit its population and the infecting probability of $R$. solanacearum on tomato plants. On the contrary, less biofilm formed by the deletion strain, P. polymyxa HY96-2- $\triangle$ luxS, would result in more physiological sites exposed on the roots of tomato plants to $R$. solanacearum, and more nutrition would be available to $R$. solanacearum, which would increase the incidence of bacterial wilt in tomato plants.

In summary, luxS played an important role in P. polymyxa HY96-2 biofilm formation and biocontrol efficacy against $R$. solanacearum. According to our results, it could be deduced that luxS improved the biofilm formation of P. polymyxa HY96-2 and then further promoted its biocontrol efficacy against $R$. solanacearum. This result could be used to guide the development of field application technology of the microbial pesticides with $P$. polymyxa HY96-2 and provide a scientific basis for improving the field biocontrol efficacy of industrialized P. polymyxa HY96-2 products. These results could also provide a reference for investigating the effect of QS systems on the biocontrol efficacy of other biocontrol agents.

Acknowledgments We thank Professor Binghai Du of Shandong Agricultural University for providing plasmid pDG1661 and pRN5101. We thank Professor Jie Bao of East China University of Science and Technology for providing plasmid pMA5.

Funding information This work was financially supported by the National Key Research and Development Program of China (2017YFD0201107-2-3) and the National Natural Science Fund (31501693).

\section{Compliance with ethical standards}

Conflict of interest The authors declare that they have no conflict of interest.

Ethical approval This article does not contain any studies with human participants or animals performed by any of the authors.

Open Access This article is distributed under the terms of the Creative Commons Attribution 4.0 International License (http:// creativecommons.org/licenses/by/4.0/), which permits unrestricted use, distribution, and reproduction in any medium, provided you give appropriate credit to the original author(s) and the source, provide a link to the Creative Commons license, and indicate if changes were made.

\section{References}

Ali F, Yao ZJ, Li WX, Sun LN, Lin WX, Lin XM (2018) In-silico prediction and modeling of the quorum sensing LuxS protein and inhibition of AI-2 biosynthesis in Aeromonas hydrophila. Molecules 23(10):1-22. https://doi.org/10.3390/molecules23102627 
Armbruster CE, Hong W, Pang B, Dew KE, Juneau RA, Byrd MS, Love CF, Kock ND, Swords WE (2009) LuxS promotes biofilm maturation and persistence of nontypeable Haemophilus influenzae in vivo via modulation of lipooligosaccharides on the bacterial surface. Infect Immun 77(9):4081-4091. https://doi.org/10.1128/IAI. 00320-09

Auger S, Krin E, Aymerich S, Gohar M (2006) Autoinducer 2 affects biofilm formation by Bacillus cereus. Appl Environ Microbiol 72(1):937-941. https://doi.org/10.1128/AEM.72.1.937-941.2006

Bais HP, Fall R, Vivanco JM (2004) Biocontrol of Bacillus subtilis against infection of Arabidopsis roots by Pseudomonas syringae is facilitated by biofilm formation and surfactin production. Plant Physiol 134:307-319. https://doi.org/10.1104/pp.103.028712

Balestrino D, Haagensen JAJ, Rich C, Forestier C (2005) Characterization of type 2 quorum sensing in Klebsiella pneumoniae and relationship with biofilm formation. J Bacteriol 187(8):2870 2880. https://doi.org/10.1128/JB.187.8.2870-2880.2005

Bassler BL (2002) Small talk: cell to cell communication in bacteria. Cell 109:421-424. https://doi.org/10.1016/s0092-8674(02)00749-3

Berg G (2009) Plant-microbe interactions promoting plant growth and health: perspectives for controlled use of microorganisms in agriculture. Appl Microbiol Biotechnol 84(1):11-18. https://doi.org/10. 1007/s00253-009-2092-7

Christiaen SEA, Motherway MO, Bottacini F, Lanigan N, Casey PG, Huys G, Nelis HJ, van Sinderen D, Coenye T (2014) Autoinducer2 plays a crucial role in gut colonization and probiotic functionality of Bifidobacterium breve UCC2003. PLoS One 9(5):1-13. https:// doi.org/10.1371/journal.pone.0098111

Duanis-Assaf D, Steinberg D, Chai Y, Shemesh M (2015) The LuxS based quorum sensing governs lactose induced biofilm formation by Bacillus subtilis. Front Microbiol 6:1-10. https://doi.org/10. 3389/fmicb.2015.01517

Fan L, Zhang DJ, Liu ZH, Tao LM, Luo YC (2012) Antifungal lipopeptide produced by Paenibacillus polymyxa HY96-2. Nat Prod Res Dev 24:729-735. https://doi.org/10.1007/s00253-0135157-6

Flemming HC, Wingender J (2010) The biofilm matrix. Nat Rev Microbiol 8(9):623-633. https://doi.org/10.1038/nrmicro2415

Galloway WRJD, Hodgkinson JT, Bowden SD, Welch M, Spring DR (2011) Quorum sensing in Gram-negative bacteria: small-molecule modulation of AHL and AI-2 quorum sensing pathways. Chem Rev 111(1):28-67. https://doi.org/10.1021/cr100109t

Galloway WRJD, Hodgkinson JT, Bowden S, Welch M, Spring DR (2012) Applications of small molecule activators and inhibitors of quorum sensing in Gram-negative bacteria. Trends Microbiol 20(9): 449-458. https://doi.org/10.1016/j.tim.2012.06.003

Gao L, Deng Y, Lu ZX, Lv FX, Bie XM (2014) Optimization of electroporation conditions for Paenibacillus polymyxa JSa-9. Food Sci 35(11):89-94. https://doi.org/10.7506/spkx1002-6630-201411018

Genin S, Boucher C (2004) Lessons learned from the genome analysis of Ralstonia solanacearum. Annu Rev Phytopathol 42:107-134. https://doi.org/10.1146/annurev.phyto.42.011204.104301

Gu Y, Li B, Tian JJ, Wu R, He YF (2018) The response of LuxS/AI-2 quorum sensing in Lactobacillus fermentum 2-1 to changes in environmental growth conditions. Ann Microbiol 68(5):287-294. https://doi.org/10.1007/s13213-018-1337-z

Haggag WM, Timmusk S (2010) Colonization of peanut roots by biofilm-forming Paenibacillus polymyxa initiates biocontrol against crown rot disease. J Appl Microbiol 104(4):961969. https://doi.org/10.1111/j.1365-2672.2007.03611.x

Han XG, Lu CP (2009) In vitro biosynthesis of autoinducer 2 of Steptococcus suis serotype 2 using recombinant LuxS and Pfs. Enzyme Microb Technol 44:40-45. https://doi.org/10.1016/j. enzmictec.2008.09.009

Hosohama-Saito K, Kokubu E, Okamoto-Shibayama K, Kita D, Katakura A, Ishihara K (2016) Involvement of luxS in biofilm formation by Capnocytophaga ochracea. PLoS One 11(1):1-18. https://doi.org/10.1371/journal.pone.0147114

Ji XL, Lu GB, Gai YP, Zheng CC, Mu ZM (2008) Biological control against bacterial wilt and colonization of mulberry by an endophytic Bacillus subtilis strain. FEMS Microbiol Ecol 65(3):565-573. https://doi.org/10.1111/j.1574-6941.2008.00543.x

Kalantari S, Marefat A, Naseri B, Hemmati R (2018) Improvement of bean yield and Fusarium root rot biocontrol using mixtures of Bacillus, Pseudomonas and Rhizobium. Trop Plant Pathol 43:499 505. https://doi.org/10.1007/s40858-018-0252-y

Kim SB, Timmusk S (2013) A simplified method for gene knockout and direct screening of recombinant clones for application in Paenibacillus polymyxa. PLoS One 8(6):1-6. https://doi.org/10. 1371/journal.pone.0068092

Klein MN, Kupper KC (2018) Biofilm production by Aureobasidium pullulans improves biocontrol against sour rot in citrus. Food Microbiol 69:1-10. https://doi.org/10.1016/j.fm.2017.07.008

Li SQ, Zhang N, Zhang ZH, Luo J, Shen B, Zhang RF, Shen QR (2012) Antagonist Bacillus subtilis HJ5 controls Verticillium wilt of cotton by root colonization and biofilm formation. Biol Fertil Soils 49(3): 295-303. https://doi.org/10.1007/s00374-012-0718-X

Li CY, Hu WC, Pan B, Liu Y, Yuan SF, Ding YY, Li R, Zheng XY, Shen B, Shen Q (2017) Rhizobacterium Bacillus amyloliquefaciens strain SQRT3-mediated induced systemic resistance controls bacterial wilt of tomato. Pedosphere 27(6):1135-1146. https://doi.org/10.1016/ s1002-0160(17)60406-5

Liu SL, Du K (2012) Enhanced expression of an endoglucanase in Bacillus subtilis by using the sucrose-inducible $s a c B$ promoter and improved properties of the recombinant enzyme. Protein Expression Purif 83(2):164-168. https://doi.org/10.1016/j.pep.2012.03.015

Liu J, Li W, Zhu X, Zhao H, Lu Y, Zhang C, Lu Z (2019) Surfactin effectively inhibits Staphylococcus aureus adhesion and biofilm formation on surfaces. Appl Microbiol Biotechnol 103(11):45654574. https://doi.org/10.1007/s00253-019-09808-w

Lombardia E, Rovetto AJ, Arabolaza AL, Grau RR (2006) A LuxSdependent cell-to-cell language regulates socialbehavior and development in Bacillus subtilis. J Bacteriol 188(12):4442-4452. https:// doi.org/10.1128/jb.00165-06

Lugtenberg BJJ, Dekkers LC (1999) What makes Pseudomonas bacteria rhizosphere competent? Environ Microbiol 1(1):9-13. https://doi. org/10.1046/j.1462-2920.1999.00005.x

Luo YC, Cheng YJ, Yi JC, Zhang ZJ, Luo Q, Zhang DJ, Li YG (2018) Complete genome sequence of industrial biocontrol strain Paenibacillus polymyxa HY96-2 and further analysis of its biocontrol mechanism. Front Microbiol 9:1-14. https://doi.org/10.3389/ fmicb.2018.01520

Ma RH, Qiu SW, Jiang Q, Sun HP, Xue T, Cai G, Sun BL (2017a) AI-2 quorum sensing negatively regulates $r b f$ expression and biofilm formation in Staphylococcus aureus. Int J Med Microbiol 307(4-5): 257-267. https://doi.org/10.1016/j.ijmm.2017.03.003

Ma YP, Hao L, Ke H, Liang ZL, Ma JY, Liu ZX, Li YG (2017b) LuxS/ AI-2 in Streptococcus agalactiae reveals a key role in acid tolerance and virulence. Res Vet Sci 115:501-507. https://doi.org/10.1016/j. rvsc.2017.07.032

Mah TFC, O'Toole GA (2001) Mechanisms of biofilm resistance to antimicrobial agents. Trends Microbiol 9(1):34-39. https://doi.org/10. 1016/s0966-842x(00)01913-2

Marian M, Nishioka T, Koyama H, Suga H, Shimizu M (2018) Biocontrol potential of Ralstonia sp. TCR112 and Mitsuaria sp. TWR114 against tomato bacterial wilt. Appl Soil Ecol 128:71-80. https://doi.org/10.1016/j.apsoil.2018.04.005

Merritt J, Qi FX, Goodman SD, Anderson MH, Shi WY (2003) Mutation of luxS affects biofilm formation in Streptococcus mutans. Infect Immun 71(4):1972-1979. https://doi.org/10.1128/iai.71.4.19721979.2003 
Miller MB, Bassler BL (2001) Quorum sensing in bacteria. Annu Rev Microbiol 55:165-199. https://doi.org/10.1146/annurev. micro.55.1.165

Niu C, Robbins CM, Pittman KJ, Osborn JL, Stubblefield BA, Simmons RB, Gilbert ES (2013) LuxS influences Escherichia coli biofilm formation through autoinducer-2-dependent and autoinducer-2independent modalities. FEMS Microbiol Ecol 83(3):778-791. https://doi.org/10.1111/1574-6941.12034

Omomowo IO, Fadiji AE, Omomowo OI (2018) Assessment of bioefficacy of Glomus versiforme and Trichoderma harzianum in inhibiting powdery mildew disease and enhancing the growth of cowpea. Ann Agric Sci 63(1):9-17. https://doi.org/10.1016/j.aoas. 2018.03.001

O'Toole G, Kaplan HB, Kolter R (2000) Biofilm formation as microbial development. Annu Rev Microbiol 54(1):49-79. https://doi.org/10. 1146/annurev.micro.54.1.49

Raafat MM, Ali-Tammam M, Ali AE (2019) Quorum quenching activity of Bacillus cereus isolate 30b confers antipathogenic effects in Pseudomonas aeruginosa. Infect Drug Resist 12:1583-1596. https://doi.org/10.2147/IDR.S182889

Ren XL, Zhang N, Cao MH, Wu K, Shen QR, Huang QW (2012) Biological control of tobacco black shank and colonization of tobacco roots by a Paenibacillus polymyxa strain C5. Biol Fertil Soils 48: 613-620. https://doi.org/10.1007/s00374-011-0651-4

Rezzonico F, Smits THM, Duffy B (2012) Detection of AI-2 receptors in genomes of Enterobacteriaceae suggests a role of type-2 quorum sensing in closed ecosystems. Sensors 12:6645-6665. https://doi. org $/ 10.3390 / \mathrm{s} 120506645$

Rickard AH, Palmer RJ, Blehert DS, Campagna SR, Semmelhack MF, Egland PG, Bassler BL, Kolenbrander PE (2006) Autoinducer 2: a concentration-dependent signal for mutualistic bacterial biofilm growth. Mol Microbiol 60(6):1446-1456. https://doi.org/10.1111/j. 1365-2958.2006.05202.x

Sela S, Frank S, Belausov E, Pinto R (2006) A mutation in the luxS gene influences Listeria monocytogenes biofilm formation. Appl Environ Microbiol 72(8):5653-5658. https://doi.org/10.1128/AEM.00048-06

Shen M, Xia D, Yin ZF, Zhao QX, Kang YX (2017) Bacillus pumilus WP8 exhibits biocontrol efficacy against tomato bacterial wilt via attenuation of the virulence of the pathogenic bacterium. Acta Agric Scand, Sect B 68(5):1-9. https://doi.org/10.1080/09064710.2017. 1416663

Sun ZK, He X, Brancaccio VF, Yuan J, Riedel CU (2014) Bifidobacteria exhibit LuxS-dependent autoinducer 2 activity and biofilm formation. PLoS One 9(2):1-8. https://doi.org/10.1371/journal.pone. 0088260

Tal-Gan Y, Ivancic M, Cornilescu G, Blackwell HE (2016) Characterization of structural elements in native autoinducing peptides and non-native analogues that permit the differential modulation of AgrC-type quorum sensing receptors in Staphylococcus aureus. Org Biomol Chem 14(1):113-121. https://doi.org/10.1039/ c5ob01735a

Thokchom E, Thakuria D, Kalita MC, Sharma CK, Talukdar NC (2017) Root colonization by host-specific rhizobacteria alters indigenous root endophyte and rhizosphere soil bacterial communities and promotes the growth of mandarin orange. Eur J Soil Biol 79:48-56. https://doi.org/10.1016/j.ejsobi.2017.02.003

Timmusk S, Grantcharova N, Wagner EG (2005) Paenibacillus polymyxa invades plant roots and forms biofilms. Appl Environ Microbiol 71(11): 7292-7300. https://doi.org/10.1128/AEM.71.11.7292-7300.2005

Timmusk S, van West P, Gow NAR, Huffstutler RP (2009) Paenibacillus polymyxa antagonizes oomycete plant pathogens Phytophthora palmivora and Pythium aphanidermatum. J Appl Microbiol 106(5):1473-1481. https://doi.org/10.1111/j.1365-2672.2009. 04123.x
Timmusk S, Copolovici D, Copolovici L, Teder T, Nevo E, Behers L (2019) Paenibacillus polymyxa biofilm polysaccharides antagonise Fusarium graminearum. Sci Rep 9(1):1-11. https://doi.org/10. 1038/s41598-018-37718-w

Vidal JE, Ludewick HP, Kunkel RM, Zahner D, Klugman KP (2011) The LuxS-dependent quorum-sensing system regulates early biofilm formation by Streptococcus pneumoniae strain D39. Infect Immun 79(10):4050-4060. https://doi.org/10.1128/IAI.05186-11

Vlamakis H, Chai YR, Beauregard P, Losick R, Kolter R (2013) Sticking together: building a biofilm the Bacillus subtilis way. Nat Rev Microbiol 11(3):157-168. https://doi.org/10.1038/nrmicro2960

Wang Y, Zhang W, Wu ZF, Zhu XL, Lu CP (2011) Functional analysis of luxS in Streptococcus suis reveals a key role in biofilm formation and virulence. Vet Microbiol 152(1-2):151-160. https://doi.org/10. 1016/j.vetmic.2011.04.029

Wang N, Wang LY, Zhu K, Hou SS, Chen L, Mi DD, Gui Y, Qi YJ, Jiang CH, Guo JH (2019) Plant root exudates are involved in Bacillus cereus AR156 mediated biocontrol against Ralstonia solanacearum. Front Microbiol 10:1-14. https://doi.org/10.3389/fmicb.2019. 00098

Wei HL, Zhang LQ (2006) Quorum-sensing system influences root colonization and biological control ability in Pseudomonas fluorescens 2P24. Antonie van Leeuwenhoek 89(2):267-280. https://doi.org/10. 1007/s10482-005-9028-8

Whitehead NA, Barnard AM, Slater H, Simpson NJ, Salmond GP (2001) Quorum-sensing in Gram-negative bacteria. FEMS Microbiol Rev 25(4):365-404. https://doi.org/10.1016/s0168-6445(01)00059-6

Woodcock DM, Crowther PJ, Doherty J, Jefferson S, DeCruz E, NoyerWeidner M, Smith SS, Michael MZ, Graham MW (1989) Quantitative evaluation of Escherichia coli host strains for tolerance to cytosine methylation in plasmid and phage recombinants. Nucleic Acids Res 17:3469-3478. https://doi.org/10.1093/nar/17.9.3469

Xu L, Li HL, Vuong C, Vadyvaloo V, Wang JP, Yao YF, Otto M, Gao Q (2006a) Role of the luxS quorum-sensing system in biofilm formation and virulence of Staphylococcus epidermidis. Infect Immun 74(1):488-496. https://doi.org/10.1128/IAI.74.1.488-496.2006

$\mathrm{Xu} \mathrm{L}$, Wang W, Wei HG, Shen GM, Li YG (2006b) Effect of Paenibacillus polymyxa HY96-2 on bacterial wilt of tomato. Chin J Biol Control 22(3):216-220. https://doi.org/10.3969/j.issn.2095039X.2006.03.012

Xu SD, Yang N, Zheng SY, Yan F, Jiang CH, Yu YY, Guo JH, Chai YR, Chen Y (2017) The spoOA-sinI-sinR regulatory circuit plays an essential role in biofilm formation, nematicidal activities, and plant protection in Bacillus cereus AR156. Mol Plant Microbe Interact 30(8):603-619. https://doi.org/10.1094/MPMI-02-17-0042-R

Yang CH, Ho GD (1998) Resistance and susceptibility of Arabidopsis thaliana to bacterial wilt caused by Ralstonia solanacearum. Phytopathology 88(4):330-334. https://doi.org/10.1094/PHYTO. 1998.88.4.330

Yang Y, Zhou MX, Hou HY, Zhu J, Yao FH, Zhang XJ, Zhu XF, Hardwidge PR, Zhu GQ (2014) Quorum-sensing gene luxS regulates flagella expression and Shiga-like toxin production in F18ab Escherichia coli. Can J Microbiol 60:355-361. https://doi.org/10. 1139/cjm-2014-0178

Yegorenkova IV, Tregubova KV, Matora LY, Burygin GL, Ignatov VV (2011) Biofilm formation by Paenibacillus polymyxa strains differing in the production and rheological properties of their exopolysaccharides. Curr Microbiol 62(5):1554-1559. https://doi. org/10.1007/s00284-011-9896-2

Yegorenkova IV, Tregubova KV, Ignatov VV (2013) Paenibacillus polymyxa rhizobacteria and their synthesized exoglycans in interaction with wheat roots: colonization and root hair deformation. Curr Microbiol 66:481-486. https://doi.org/10.1007/s00284-012-0297-y 
Yoshida A, Ansai T, Takehara T, Kuramitsu HK (2005) LuxS-based signaling affects Streptococcus mutans biofilm formation. Appl Environ Microbiol 71(5):2372-2380. https://doi.org/10.1128/ AEM.71.5.2372-2380.2005

Zhang GQ, Bao P, Zhang Y, Deng AH, Chen N, Wen TY (2011) Enhancing electro-transformation competency of recalcitrant Bacillus amyloliquefaciens by combining cell-wall weakening and cell-membrane fluidity disturbing. Anal Biochem 409:130-137. https://doi.org/10.1016/j.ab.2010.10.013
Zhang L, Cao C, Jiang RF, Xu H, Xue F, Huang WW, Ni H, Gao J (2018) Production of R,R-2,3-butanediol of ultra-high optical purity from Paenibacillus polymyxa ZJ-9 using homologous recombination. Bioresour Technol 261:272-278. https://doi.org/10.1016/j.biortech. 2018.04.036

Publisher's note Springer Nature remains neutral with regard to jurisdictional claims in published maps and institutional affiliations. 